\title{
Minimally invasive surgery for esophageal achalasia
}

\author{
Huan-Wen Chen, Ming Du \\ Department of Cardiothoracic Surgery, the First Affiliated Hospital of Chongqing Medical University, Chongqing 400016, China \\ Correspondence to: Ming Du. Doctor Medicinae, tutor for graduate, associate chief physician, the First Affiliated Hospital of Chongqing Medical \\ University, Chongqing 400016, China. Email: 1jdyt1103@sina.com.
}

\begin{abstract}
Esophageal achalasia is due to the esophagus of neuromuscular dysfunction caused by esophageal functional disease. Its main feature is the lack of esophageal peristalsis, the lower esophageal sphincter pressure and to reduce the swallow's relaxation response. Lower esophageal muscular dissection is one of the main ways to treat esophageal achalasia. At present, the period of muscular layer under the thoracoscope esophagus dissection is one of the treatment of esophageal achalasia. Combined with our experience in minimally invasive esophageal surgery, to improved incision and operation procedure, and adopts the model of the complete period of muscular layer under the thoracoscope esophagus dissection in the treatment of esophageal achalasia.
\end{abstract}

Keywords: Video-assisted thoracic surgery (VATS); minimally invasive surgery; esophageal achalasia

Submitted May 10, 2016. Accepted for publication May 17, 2016.

doi: $10.21037 /$ jtd.2016.06.35

View this article at: http://dx.doi.org/10.21037/jtd.2016.06.35

\section{Introduction}

Achalasia is an esophageal motor disorder characterized by aperi-stalsis of the esophageal body and loss of relaxation of the lower esophageal sphincter, leading to progressive dysphagia and regurgitation. Treatment is mainly to alleviate the functional obstruction caused by lower esophageal sphincter for the purpose, at the same time maintain lower esophageal sphincter pressure and prevent the balance between the gastroesophageal reflux disease. Its existing treatments include drug therapy, interventional therapy, surgical treatment and so on, the current medications include calcium channel blockers and long-acting nitrates (1), but the worst oral drug therapy in the treatment of little effect (2), endoscopic balloon dilatation (endoscopic pneumatic dilation, EPD) for esophageal achalasia is considered to be treated the most effective non-surgical treatment (3), which is the most serious complications of perforation, the incidence of $<1-3 \%$ (4). Lower esophageal muscular dissection is one of the main ways to treat the disease of esophageal achalasia, but the traditional open surgery, trauma, postoperative complications, especially for young patients to accept. In the early 1990s began to use thoracoscope surgery. In 1992, Pellegrini (5) to carry out the period of muscular layer under the thoracoscope esophagus dissection in the treatment of esophageal achalasia. Then the technology is widely used (6-9). Combined with our experience in minimally invasive esophageal surgery, to improved incision and operation procedure, and adopts the model of the complete period of muscular layer under the thoracoscope esophagus dissection in the treatment of esophageal achalasia. This paper is aim to describe it.

\section{Minimally invasive surgery for esophageal achalasia}

The patient is intubated with a double lumen endotracheal tube with single-lung ventilation and intravenous anesthesia. The patient was placed in a lateral position. The surgeon stood in an anterior position to the patient. Three ports were use in this surgery. A thoracoscope was placed in the $7^{\text {th }}$ intercostal space at the mid-axillary line. A working port $(0.5 \mathrm{~cm})$ was located in the mid-axillary line in the $4^{\text {th }}$ intercostals. A assistant port was located in the $9^{\text {th }}$ intercostal space between the posterior axillary line and subscapular line. 


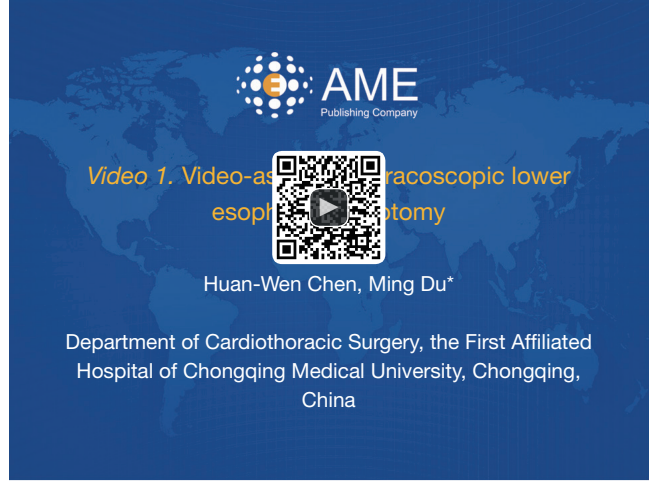

Figure 1 Video-assisted thoracoscopic lower esophageal myotomy (10). Available online: http://www.asvide.com/articles/1033

\section{Minimally invasive surgery for esophageal achalasia (Figure 1) is divided into steps:}

(I) First of all, marked by descending aorta, mediastinal pleura, USES electric coagulation hook under the esophagus free segment esophageal dorsal, marked by pericardium and mediastinal pleura free segment esophageal ventral, esophageal set of belt;

(II) Cut by electric coagulation hook esophagus to longitudinal and circular muscle layer in $8-10 \mathrm{~cm}$ above, showing the esophageal mucosa. Cut esophageal muscular layer to gastric esophagus connection department the following $0.5-1 \mathrm{~cm}$;

(III) About half of the pipe diameter exposed esophageal mucosa. The stomach tube to cut parts, inflatable, observed under endoscopy esophageal mucosa without leakage, bleeding, one chest tube root.

\section{Discussion}

Esophageal achalasia is due to the esophagus of neuromuscular dysfunction caused by esophageal functional disease. Its main feature is the lack of esophageal peristalsis, the lower esophageal sphincter pressure and to reduce the swallow's relaxation response. Clinical manifestation of dysphagia, retrosternal pain, food reflux and pulmonary aspiration caused such as cough, lung infection. Its incidence is about $1 / 10$ a year, similar incidence between men and women, about 1 to 1.15 . The disease occurs in 20-50 years old of young adults, but other age groups also can occur, much longer duration. Lower esophageal muscular dissection is one of the main ways to treat esophageal achalasia, but the traditional open surgery, trauma, postoperative complications, especially for young patients to accept. At present, the period of muscular layer under the thoracoscope esophagus dissection is one of the treatment of esophageal achalasia (11). Relative abdominal cardiac muscle layer cut bottom folding cocktail, thoracoscope exposed cardia is relatively easy, cut open and peel muscularis and fully, less chance of mucosal injury, surgery can clear esophageal stricture, muscular cut narrow place not free all week, esophagus to reduce postoperative surrounding tissues of postoperative adhesion, reduce the recurrence rate and shorten the operation time, especially for obese people, thoracoscope damage to cardiac structure is small, they don't need to line the bottom of the stomach folding, abdominal approach damaged cardiac structure, the incidence of postoperative gastroesophageal reflux group is higher than the chest. Undergraduate course room from 2008 with the help of esophageal chest laparoscopic resection $(12,13)$, with his experience in minimally invasive esophageal surgery, for improved incision and operating procedures. In endoscopy surgery, the design of the incision is usually placed in a very important position, its reason is: incision is close to the target area or to form the Angle of the target area, these factors will affect the operation of fluency, and will increase the difficulty of the operation. In addition, we use artificial pneumothorax chest cavity filling carbon dioxide gas, make better collapsed lung, and the diaphragm down better exposure period of esophagus. And under the condition of artificial pneumothorax, widened mediastinum sapce could faciliate the operative procedure and reduce the blood loss. Each step the operation has simpler anatomy marks guidance, beginners just to recognize these signs, carried out in accordance with the procedures of the machinery, can be smoothly carried out the operation.

\section{Conclusions}

To sum up, Heller under thoracoscope surgery with small trauma, rapid recovery, less complications, shorter hospitalization time and other characteristics, can be used as one of the treatment of esophageal achalasia.

\section{Acknowledgements}

None.

\section{Footnote}

Conflicts of Interest: The authors have no conflicts of interest to declare. 


\section{References}

1. Hoogerwerf WA, Pasricha PJ. Pharmacologic therapy in treating achalasia. Gastrointest Endosc Clin N Am 2001;11:311-24, vii.

2. Wang S, Liu BR. Recent progress in treatment of achalasia. World Chinese Journal of Digestology 2013;21:75-81.

3. Galassi G, Orlandi C, Valzania F, et al. Botulin toxin type A (BTA) for esophageal achalasia: a double-edged sword. Int J Colorectal Dis 2011;26:1079-80.

4. Hulselmans M, Vanuytsel T, Degreef T, et al. Longterm outcome of pneumatic dilation in the treatment of achalasia. Clin Gastroenterol Hepatol 2010;8:30-5.

5. Pellegrini C, Wetter LA, Patti M, et al. Thoracoscopic esophagomyotomy. Initial experience with a new approach for the treatment of achalasia. Ann Surg 1992;216:291-6; discussion 296-9.

6. Patti MG, Fisichella PM, Perretta S, et al. Impact of minimally invasive surgery on the treatment of esophageal achalasia: a decade of change. J Am Coll Surg 2003;196:698-703; discussion 703-5.

7. Fernández AF, Martínez MA, Ruiz J, et al. Six years of experience in laparoscopic surgery of esophageal achalasia.
Surg Endosc 2003;17:153-6.

8. Bonavina L. Minimally invasive surgery for esophageal achalasia. World J Gastroenterol 2006;12:5921-5.

9. Codispoti M, Soon SY, Pugh G, et al. Clinical results of thoracoscopic Heller's myotomy in the treatment of achalasia. Eur J Cardiothorac Surg 2003;24:620-4.

10. Chen HW, Du M. Video-assisted thoracoscopic lower esophageal myotomy. Asvide 2016;3:271. Available online: http://www.asvide.com/articles/1033

11. Huang Y, Li X, Liu J, et al. Video-assisted thoracoscopic lower esophageal myotomy in the management of achalasia: A report of 21 cases. Chinese Journal of Minimally Invasive Surgery 2005;5:611-3.

12. Du M, Chen H, Wu Q, et al. Thoracoscopic and laparoscopic esophagectomy for esophageal carcinoma: report of 40 cases. Acta Academiae Medicinae Militaris Tertiae 2010;32:1068-70.

13. Chen H, Du M, Wu Q, et al. Evaluation in patients with different gastric tube reconstruction after esophagectomy with thoracoscopy and laparoscopy for esophageal carcinoma. Journal of Chongqing Medical University 2010;35:788-90.
Cite this article as: Chen HW, Du M. Minimally invasive surgery for esophageal achalasia. J Thorac Dis 2016;8(7):18341836. doi: $10.21037 /$ jtd.2016.06.35 